\title{
Residual Stress State of X65 Pipeline Girth Welds before and after Local and Furnace Post Weld Heat Treatment
}

\author{
Yao Ren ${ }^{1}$ \\ Brunel University/NSIRC \\ London, UK \\ yao.ren@brunel.ac.uk \\ Anna Paradowska \\ ANSTO \\ Sydney, Australia \\ anp@ansto.gov.au \\ Bin Wang \\ Brunel University \\ London, UK \\ bin.wang@brunel.ac.uk
}

\section{Elvin Eren}

TWI Ltd

Cambridge, UK

elvin.eren@twi.co.uk

\section{Yin Jin Janin}

TWI Ltd

Cambridge, UK

yin.jin.janin@twi.co.uk

\section{ABSTRACT}

This research investigated the effects of global (in other words, furnace-based) and local post weld heat treatment (PWHT) on residual stress (RS) relaxation in API 5 L X65 pipe girth welds. All pipe spools were fabricated using identical pipeline production procedures for manufacturing multi-pass narrow gap welds. Non-destructive neutron diffraction (ND) strain scanning was carried out on girth welded pipe spools and strain-free comb samples for the determination of the lattice spacing. All residual stress

\footnotetext{
${ }^{1}$ Corresponding author information can be added as a footnote.
} 
Journal of Pressure Vessel Technology

measurements were carried out at the KOWARI strain scanning instrument at the Australian Nuclear Science and Technology Organization (ANSTO).

Residual stresses were measured on two pipe spools in as-welded condition and two pipe spools after local and furnace PWHT. Measurements were conducted through the thickness in the weld material and adjacent parent metal starting from the weld toes. Besides, three line-scans along pipe length were made $3 \mathrm{~mm}$ below outer surface, at pipe wall mid-thickness and $3 \mathrm{~mm}$ above the inner surface. PWHT was carried out for stress relief; one pipe was conventionally heat treated entirely in an enclosed furnace and the other was locally heated by a flexible ceramic heating pad. Residual stresses measured after PWHT were at exactly the same locations as those in as-welded condition.

Residual stress states of the pipe spools in as-welded condition and after PWHT were compared and the results were presented in full stress maps. Additionally, through-thickness residual stress profiles and the results of one line scan (3mm below outer surface) were compared with the respective residual stress profiles advised in British Standard BS 7910 "Guide to methods for assessing the acceptability of flaws in metallic structures" and the UK nuclear industry's $R 6$ procedure. The residual stress profiles in as-welded condition were similar. With the given parameters, local PWHT has effectively reduced residual stresses in the pipe spool to such a level that it prompted the thought that local PWHT can be considered a substitute for global PWHT.

\section{INTRODUCTION}

A weld joint consists of three metallurgical different regions, namely weld metal, heat affected zone (HAZ) and parent metal. Residual stresses are introduced during welding as a result of parent metal restraint on the shrinkage of hot weld metal during cooling - due to thermal expansion and contraction - and/or simultaneous microstructural phase transformation [1].

In a weldment, residual stresses can possibly be as high as the material's yield strength or even higher at room temperature. In industrial production, one of the 
reasons for the preference multi-pass narrow gap welding is the relatively lower heat input during welding, resulting in a smaller heat affected zone. Lower heat input also introduces lower levels of residual stresses [2].

Many experimental investigations have been carried out for determining the residual stress distribution and magnitude in pipes, both at the surface and through wall thickness [3], [4]. Destructive and non-destructive residual stress measurement techniques have been employed [5] with the latter being more commonly used. Among the non-destructive techniques, neutron diffraction has a number of distinct merits. A neutron beam wave length is comparable to atomic spacing [6]. This technique has the advantage of penetrating subsurface and deeply inside the bulk of material up to several centimetres, and it provides a three dimensional residual stress state. The technique has been successfully utilized to investigate residual stresses in pipe girth welds [7]-[9].

Post weld heat treatment (PWHT) is applied after welding, aiming at reducing residual stresses in thick-walled components and thus improving the structural integrity performance (conversely, PWHT is used in some structures for the purpose of controlling distortion after welding). It is an optional procedure in fabrication practice, and the need for this is largely dependent on the grade of the material, component thickness and the criticality of application. PWHT is commonly conducted in an enclosed furnace for a few hours to remove the hydrogen, improve fracture toughness and relax residual stresses in components when possible. However, in the circumstances that conventional furnace PWHT is not feasible, local PWHT can be considered as an alternative for the application of which equipment availability, geometry of the 
structure, fabrication requirements and working environment should be all taken into consideration [10].

In terms of relief of residual stresses, the PWHT holding temperature has been demonstrated to be more critical than the holding time. Information on the effectiveness of PWHT has been incorporated into industrial standards and codes such as BS 7910 [11], which assumes that in wide grove welds, different levels of stress relief occur in both transverse and longitudinal directions following a conventional furnace PWHT. BS7910 also provides information on the effect of PWHT temperature. However, the guidance provided is not intended to be relevant to narrow gap welds. In addition, the information regarding the degree of stress relief after local PWHT is still limited; although some practical work with regard to local PWHT has been carried out experimentally and analytically to investigate the effective heating band width for stress relaxation [12]-[15] and through-thickness temperature gradient criteria [16]-[18].

In this work, stresses in narrow gap girth welds in pipe spools were measured, both in the as-welded condition and after global and local PWHT. Residual stress distributions were identified non-destructively by neutron diffraction and compared with the recommendations given in two engineering critical assessment procedures; BS 7910 and R6 [19].

\section{GIRTH WELD FABRICATION}

\section{Material properties}

The parent material is APL $5 \mathrm{~L}$ X65 pipeline steel. Chemical compositions of the parent and filler metal are listed in Table 1. The specifications of the pipes used in this 
study are: $750 \mathrm{~mm}$ long with an outer diameter $D$ in $355.6 \mathrm{~mm}$ (14inch.) and a wall thickness $t$ in $19.05 \mathrm{~mm}$ (3/4 inch.). As the standard dimension ratio $\mathrm{D} / \mathrm{t}$ of the pipe is 18 , it is regarded as thick-wall pipe.

Tensile properties of both parent and weld material were obtained from tests carried out on the specimens extracted from one of the girth welded pipe spools. All weld metal specimens were extracted along the girth weld in the hoop direction. Parent metal samples were extracted parallel to the pipe axis. All tests were conducted according to British Standard BS EN ISO 6892 at ambient temperature and the results are presented in Table 2.

\section{Welding Procedure}

Welding of the pipe spools was carried out in accordance with a conventional industrial manufacturing specification. The fabricated final pipe spool was $1500 \mathrm{~mm}$ long with a multi-pass narrow gap girth weld in the middle. Figure 1 exhibits the geometry of the weld groove and the schematic representation of the welding procedure. The small angled J-bevel groove geometry and a slight bevel offset created a narrow gap weld profile. Six passes of the filler metal were deposited.

Before welding, a pipe piece was initially bullet tacked to an anchor pipe to fix one pipe end. Then the second pipe piece was skin tacked with the first one at four locations based on the welding specification (2, 4, 7 and 11 o'clock circumferential locations). Each tack was approximately $25 \mathrm{~mm}$ long. The weld groove and adjacent parent metal (150mm on each side) were then preheated by induction heating. Pipe spool $\mathrm{P}_{\mathrm{Aw}} 1$ (to be denoted as " $\mathrm{P}_{\mathrm{Aw}} 1$ " for the residual stress measurement in as-welded condition) was only 
preheated on one side of the weld groove and adjacent parent metal, because of a numbers of strain gauges and thermocouples for process monitoring were attached on the other side. Pipe spool $\mathrm{P}_{\mathrm{Aw}} 2$ (to be denoted as " $\mathrm{P}_{\mathrm{Aw}} 2$ " for the residual stress measurement in as-welded condition) was preheated on both sides. Preheating is intended to avoid hydrogen cracking, the effect (if any) of preheating [20], [21] on welding residual stresses was also part of the investigation in the study.

During welding, the pipe sections were fixed horizontally and no clamping was applied. Two mechanically and electrically controlled welding torches were used and welds were laid simultaneously on both sides. Each of them was deposited a weld along the pipe circumference 180 degree from the 12 o'clock (weld start) to the 6 o'clock (weld stop) position. The weld contains a root pass, a hot pass, three fills and the cap. The root pass was completed by using cold metal transfer (CMT) technique and the rest of the passes were fabricated by pulsed gas metal arc welding (PGMAW) process.

Between each pass, a short period of time was allowed for air cooling. Inter-pass temperature was monitored and it was observed that the inter-pass temperature was in the range of $80-160^{\circ} \mathrm{C}$. Table 3 lists the welding parameters for the pipe spools fabricated.

\section{RESIDUAL STRESS MEASUREMENT}

\section{Principles of neutron diffraction}

Residual stress states in pipe girth welds were assessed using neutron diffraction (ND). The principles of ND are based on Bragg's and Hooke's Laws. In a polycrystalline material, only the grain lattice planes which allow Bragg reflection will contribute to the 
scattering. The principle of the Bragg's law is illustrated in Figure 2 [22], [23]. Once a beam of neutrons of a wavelength $\lambda$ is incident upon a crystalline material, a diffraction pattern is produced with peaks. Let $d$ represents the lattice spacing in the direction of scattering, vector $Q$ and the scattering angle $2 \theta$ then Bragg's law gives the position of the peak value,

$$
2 \mathrm{~d} \sin \theta=\lambda
$$

In this work, measurements were made with a continuous monochromatic beam of neutrons. When a beam of neutron is diffracted on a stressed crystal plane, any change in lattice spacing $\Delta \mathrm{d}$ would result in a corresponding shift in the angular position $\Delta \theta$ of Bragg reflection when the strain-free lattice spacing $d_{0}$ is known, the lattice elastic strain $\varepsilon$ in the direction of the scattering vector can be calculated as:

$$
\varepsilon=\frac{\mathrm{d}-\mathrm{d}_{\mathrm{o}}}{\mathrm{d}_{\mathrm{o}}}=\frac{\Delta \mathrm{d}}{\mathrm{d}_{\mathrm{o}}}=-\Delta \theta \cot \theta
$$

When principal strain components $\varepsilon_{\mathrm{xx}}, \varepsilon_{\mathrm{yy}}$ and $\varepsilon_{\mathrm{zz}}$ are known, the corresponding stresses can be obtained based on continuum mechanics using the general Hooke's law:

$$
\begin{aligned}
& \sigma_{\mathrm{xx}}=\frac{\mathrm{E}}{(1+v)(1-2 v)}\left[(1-v) \varepsilon_{\mathrm{xx}}+v\left(\varepsilon_{\mathrm{yy}}+\varepsilon_{\mathrm{zz}}\right)\right] \\
& \sigma_{\mathrm{yy}}=\frac{\mathrm{E}}{(1+v)(1-2 v)}\left[(1-v) \varepsilon_{\mathrm{yy}}+v\left(\varepsilon_{\mathrm{zz}}+\varepsilon_{\mathrm{xx}}\right)\right] \\
& \sigma_{\mathrm{zz}}=\frac{\mathrm{E}}{(1+v)(1-2 v)}\left[(1-v) \varepsilon_{\mathrm{zz}}+v\left(\varepsilon_{\mathrm{xx}}+\varepsilon_{\mathrm{yy}}\right)\right]
\end{aligned}
$$

Where $\mathrm{E}$ is the Young's modulus and $\mathrm{v}$ is the Poisson's ratio of the material. Based on the Kröner model, the scattering plane for ferritic steel is Fe (211) and therefore the values of $E=223.8 \mathrm{GPa}$ and $\mathrm{v}=0.27$ are used for $\mathrm{X} 65$ steel in this work. Calculation are carried out using software DECcal [24].

\section{Instrumentation and sample preparation}


Residual stress measurements were carried out by the KOWARI strain scanning diffractometer at the Australia Nuclear Science and Technology Organization (ANSTO). A neutron wavelength of $1.67 \AA$ was obtained from a double focusing Si (400) monochromator at a take-off angle of $76^{\circ}$ to examine the $\alpha$-Fe (211) scattering plane. A gauge volume of $3 \times 3 \times 4 \mathrm{~mm}^{3}$ was used in all measurements.

The maximum length of a sample to be measured by the KOWARI instrument can be up to $1000 \mathrm{~mm}$ due to the constraint of the strain scanner. The length of the pipe spools was, therefore, reduced symmetrically to $1000 \mathrm{~mm}$ with the weld in the middle.

It is essential to obtain correct value of the stress-free lattice spacing $d_{0}$ in the reference sample [25] for calculating the residual stress. Reference samples prepared in this work as shown in Figure 3 were extracted from a similar sample at the same location in another pipe spool manufactured using the same welding parameters. Electro-discharge machining (EDM) was used to obtain a macro-strain-relived condition. The preparation of the reference sample was introduced in author's previous publication [26].

\section{ND measurement procedures}

As the main intention was to investigate the narrow gap welding procedure under a steady state condition, ND measurements were conducted at half way along the weld (at the 3 o'clock circumferential location) of the pipe (Figure 4a). Besides, it was assumed that the stress state is symmetric with regard to the weld centre. The measurement points were mainly on one side of the weld. This approach enabled an optimal use of available beam time. 
Three line-scans were carried out at a). $3 \mathrm{~mm}$ below the outer surface, b).midthickness and c).3mm above the inner surface. This allows full residual stress maps to be generated for compare of the stress states of the pipe spools in as-welded condition and after PWHT. Additional through wall thickness measurements were carried out at the weld centre and weld toe areas. Measurement points in the vicinity of the weld are illustrated in Figure 4(b).

For each pipe, residual stresses were measured at up to 40 locations. At each location, strain components were determined in three principal directions: axial, hoop and radial. As shown in Figure 5, the pipe was lying horizontally for the axial strain measurements. Hoop and radial components were measured with the pipe in the vertical position.

In order to derive an unstrained d-spacing $\left(d_{0}\right)$, the lattice spacing in the reference samples was measured at several locations in all three directions. The value of $d_{0}$ was also calculated assuming that the hoop stress in the reference sample was thoroughly relieved. It was found that there was no significant lattice spacing variations, potentially due to chemical variations, in both weld metal and parent metal, therefore the averaged values $d_{0}$ of weld and parent materials of the reference sample were used for residual stress calculations.

\section{Uncertainties of the calculated results}

The errors, or uncertainties in both the measured stressed and unstressed lattice spacing ( $\Delta \mathrm{d}$ and $\left.\Delta \mathrm{d}_{0}\right)$ were calculated by using an error propagation method [27]. There are a few possibilities contributing to $\Delta \mathrm{d}$ and $\Delta \mathrm{d}_{0}$, among which the error in the peak 
position (data fitting) can be easily quantified. This source of uncertainty is dependent on the counting time of the measurement, and is present in all lattice spacing measurements. Other sources of experimental uncertainty may be present, including thermal, grain size and texture effects [28]. The source of errors such as positioning, gauge volume size or misalignment during the experiment procedure could be minimised but not easily quantified. Derived from the error propagation method, considering only the peak fitting, the errors of elastic strains $\varepsilon_{\mathrm{xx}}, \varepsilon_{\mathrm{yy}}$ and $\varepsilon_{\mathrm{zz}}$ are written as:

$$
\begin{aligned}
& \Delta \varepsilon_{\mathrm{xx}}=\frac{\mathrm{d}_{\mathrm{xx}}}{\mathrm{d}_{0}} \sqrt{\left(\frac{\Delta \mathrm{d}_{\mathrm{xx}}}{\mathrm{d}_{\mathrm{xx}}}\right)^{2}+\left(\frac{\Delta \mathrm{d}_{0}}{\mathrm{~d}_{0}}\right)^{2}} \\
& \Delta \varepsilon_{\mathrm{yy}}=\frac{\mathrm{d}_{\mathrm{yy}}}{\mathrm{d}_{0}} \sqrt{\left(\frac{\Delta \mathrm{d}_{\mathrm{yy}}}{\mathrm{d}_{\mathrm{yy}}}\right)^{2}+\left(\frac{\Delta \mathrm{d}_{0}}{\mathrm{~d}_{0}}\right)^{2}} \\
& \Delta \varepsilon_{\mathrm{zz}}=\frac{\mathrm{d}_{\mathrm{zz}}}{\mathrm{d}_{0}} \sqrt{\left(\frac{\Delta \mathrm{d}_{\mathrm{zz}}}{\mathrm{d}_{\mathrm{zz}}}\right)^{2}+\left(\frac{\Delta \mathrm{d}_{0}}{\mathrm{~d}_{0}}\right)^{2}}
\end{aligned}
$$

Errors of the stress components can then be derived as:

$$
\begin{aligned}
& \Delta \sigma_{\mathrm{xx}}=\frac{\mathrm{E}}{(1+v)(1-2 v)} \sqrt{(1-v)^{2} \Delta^{2} \varepsilon_{\mathrm{xx}}+v^{2} \Delta^{2} \varepsilon_{\mathrm{yy}}+v^{2} \Delta^{2} \varepsilon_{\mathrm{zz}}} \\
& \Delta \sigma_{\mathrm{yy}}=\frac{\mathrm{E}}{(1+v)(1-2 v)} \sqrt{(1-v)^{2} \Delta^{2} \varepsilon_{\mathrm{yy}}+v^{2} \Delta^{2} \varepsilon_{\mathrm{zz}}+v^{2} \Delta^{2} \varepsilon_{\mathrm{xx}}} \\
& \Delta \sigma_{\mathrm{zz}}=\frac{\mathrm{E}}{(1+v)(1-2 v)} \sqrt{(1-v)^{2} \Delta^{2} \varepsilon_{\mathrm{zz}}+v^{2} \Delta^{2} \varepsilon_{\mathrm{xx}}+v^{2} \Delta^{2} \varepsilon_{\mathrm{yy}}}
\end{aligned}
$$

The reported errors are $\pm 15 \mathrm{MPa}$ on average. Note that these are the peak fitting errors and do not take into account other possible sources of errors such as partial illumination. The chance of partial illumination is considered low as there are no 
Journal of Pressure Vessel Technology

unexpected high stress results close to edges, and the error in sample positioning is estimated to be less than $0.1 \mathrm{~mm}$.

\section{PWHT ON THE PIPES}

In order to investigate the effectiveness of PWHT on the relief of residual stresses, two pipe spools were sent to an external laboratory for PWHT after measurement of the residual stresses in as-welded condition. Pipe spool $\mathrm{P}_{\mathrm{HT}} 1$ was locally heated treated by using an electrical resistance heating blanket for a period of 1 hour. Pipe spool $\mathrm{P}_{\mathrm{HT}} 2$ went through the conventional furnace heat treatment for the same length of time. A general sketch of the local circumferential PWHT parameters as well as their terminologies is provided in Figure 6 . Widths of the heating band and the gradient control band were calculated to provide the minimum values in the recommended practice [29] and are listed in Table 4. Values of the heating/cooling rates, soaking temperature and soaking time were selected based on a comparison of the recommendations given in various standards, and are also shown in Table 4.

During the heating process, reference samples (in as-welded condition) were also attached to the pipes and heated together to minimize potential errors through the differences in the thermal history. Residual stress distributions were measured again on all reference samples and pipe spools at the same locations as in the measurements of the as-welded condition.

RESIDUAL STRESS PROFILES IN CURRENT ENGINEERING CRITICAL ASSESSMENT PROCEDURES

\section{Residual stress in as-welded condition}


Engineering Critical Assessment (ECA) procedures such as BS7910 and R6 recommend through wall residual stress profiles to be used in the assessment of structures containing flaws in the absence of residual stress measurements and/or simulations.

R6 provides three levels of measurement for determining the magnitude and spatial distribution of residual stresses. In Level 1 , the structure with a defect is assessed assuming that the residual stresses are uniform and tensile with a magnitude equal to the appropriate yield stress of the parent metal or weld material. This level is equivalent to the assessment procedure described in section 7.1.8 of BS 7910. Non-uniform residual stress distributions for a range of structures are presented in Level 2 of R6, as well as in Annex Q of BS 7910. Level 2 profiles are based on published compendia of conservative residual stress profiles for a range of as-welded structures. They are upper bounds, and less conservative compared to the uniform tensile stress distribution advised in Level 1. In both BS7910 and R6 procedures, it is advised that for residual stress profile, longitudinal stresses are normalized with respect to the greater yield strength (at room temperature) of the weld or parent material (represented by $\sigma_{y}^{+}$) for the level 2. The transverse stresses, in contrast, are advised to be normalized with respect to the lower yield strength of the two (represented by $\sigma_{\mathrm{y}}^{*}$ ). The Level 3 approach (measurement and/or analysis of a specific joint) is expected to lead to less conservative results but is more complex, requiring both experimental measurements and numerical analysis. 
In terms of the stress components in pipeline girth welds, the longitudinal stress designates the stresses acting in the hoop direction (i.e. along the weld) and the transverse stress designates the stresses acting in the axial direction (i.e. transverse to the weld). The residual stress in the radial direction is negligible provided that the pipe can be considered as a thin-walled structure.

In the case of pipe butt weld geometry, Level 2 recommends a longitudinal throughthickness residual stress distribution as a linear profile. At the outer surface, the longitudinal residual stress $\sigma_{\mathrm{R}}^{\mathrm{L}, \mathrm{O}}$ equals to $\sigma_{y}^{+}$. In contrast, the residual stress at the bore (inner surface) $\sigma_{R}^{L, B}$ can be calculated by equation (12). In this study, the pipe wall thickness is in the range between 15 and $85 \mathrm{~mm}, A_{b}$ is calculated using equation (13) [11]. The specific Level 1 and 2 profiles are displayed in Figure 7(a).

$$
\begin{gathered}
\sigma_{\mathrm{R}}^{\mathrm{L}, \mathrm{B}}=\mathrm{A}_{\mathrm{b}} \sigma_{\mathrm{y}}^{+} \\
\mathrm{A}_{\mathrm{b}}=1-0.0143(\mathrm{t}-15)
\end{gathered}
$$

The through-wall transverse residual stress profiles are defined in terms of the fractional distance from the inner surface, $z / t$, and depend on the weld electrical energy per unit run length per unit thickness $[(q / v) / t]$, where $q$ is equal to current $\times$ voltage $(\mathrm{J} / \mathrm{sec}), \mathrm{v}$ is the welding torch advance rate $(\mathrm{mm} / \mathrm{sec}), \mathrm{z}$ is the radial distance from the pipe inner surface $(\mathrm{mm})$ and $\mathrm{t}$ is the pipe wall thickness $(\mathrm{mm})$. For the welding technique used in this work, the heat input $[(\mathrm{q} / \mathrm{v}) / \mathrm{t}]$ was less than $50 \mathrm{~J} / \mathrm{mm}^{2}$ and is 'low heat input' as defined in BS 7910. The transverse residual stress profiles following BS 7910 and R6 procedures are shown in Figure 7(b).

$$
\sigma_{\mathrm{R}}^{\mathrm{T}}=\sigma_{\mathrm{y}}^{*}\left[1-6.80(\mathrm{z} / \mathrm{t})+24.30(\mathrm{z} / \mathrm{t})^{2}-28.68(\mathrm{z} / \mathrm{t})^{3}+11.18(\mathrm{z} / \mathrm{t})^{4}\right]
$$


In BS 7910, there is currently no guidance on the residual stress distributions along the pipe length showing how residual stresses fade away from the weld centre-line outwards. With regard to the surface residual stress profiles, parameter $r_{0}$, given in R6, is used to define the yield zone dimension of the weld in thick materials. Ideally, residual stresses in the yield zone would be entirely tensile with infinite material restraints. In practice, finite restraints enable redistribution of residual stresses between the yield zone and the adjacent material. As a result the longitudinal residual stress in the butt weld next to the yield zone is usually compressive. To determine the radius of the yield zone $r_{0}(\mathrm{~mm})$, Equation 15 was applied, based on the R6 procedure when $r_{0} \leq t$,

$$
\mathrm{r}_{0}=\sqrt{\frac{\mathrm{K}}{\sigma_{\mathrm{YP}}} \cdot \frac{\eta \mathrm{q}}{v}}
$$

Where $\mathrm{t}$ is the pipe wall thickness $(\mathrm{mm}), \mathrm{K}$ is the material constant $(\mathrm{Nmm} / \mathrm{J}), \sigma_{\mathrm{YP}}$ is the yield or $0.2 \%$ proof strength of the parent metal $\left(\mathrm{N} / \mathrm{mm}^{2}\right), \mathrm{q}$ is the $\operatorname{arc}, \mathrm{v}$ is the welding speed and $\eta$ is the process efficiency.

Taking a typical value of efficiency of $80 \%$ i.e. $\eta=0.8, \mathrm{~K} \cdot \eta=122 \mathrm{Nmm} / \mathrm{J}$ can be assumed for ferritic steels [19]. Using the heat input experienced by the cap and measured from the fusion boundary, the yielded zone radius $r_{0}$ in this experiment was conservatively selected as the lowest value during welding. The residual stress magnitude was then assumed to be constant and equal to $\sigma_{\mathrm{YP}}$ in the weld and reduced to zero at the boundary of the yield zone. The calculated yield zone is shown in the Figure 8. 
Currently there are no recommended profiles for axial residual stress in restrained material in ECA procedures. This is because the tensile stress on the un-yielded material would spread outwards. The decay of the transverse stresses with distance varies for different cases. Conservatively, they are assumed to be constant and equal in the magnitude to the $0.2 \%$ proof strength of either parent material or the weld metal, whichever is lower.

\section{Residual stress after PWHT}

The level of residual stress relief after furnace PWHT is given in BS 7910:2013 for the carbon manganese and $2 \frac{1}{4} \mathrm{Cr} 1 \mathrm{Mo}$ steels. It is assumed that the residual stress remaining in the welds after an enclosed furnace PWHT with the range of $580^{\circ} \mathrm{C}$ to $620^{\circ} \mathrm{C}$ would be $20 \%$ of the lesser of the room temperature yield strengths of the weld or the parent metal for the stress component transverse to the weld; $30 \%$ of the room temperature yield strength of the material (the weld or the parent metal) where the flaw is located for the stress component parallel to the weld. It should be noted that this is treated as a membrane stress. It needs to be highlighted that there is currently no guidance in the procedures to estimate the level of residual stresses after local PWHT.

\section{RESIDIAL STRESS RESULTS}

Maps of the through-thickness residual stress in $\mathrm{P}_{\mathrm{AW}} 1$ and $\mathrm{P}_{\mathrm{AW}} 2$ under the as-welded condition are shown in Figure 9. It can be see that the two pipes were in a similar stress condition after welding. This implies that the differences in the preheat condition does not affect the stress profile significantly. The highest hoop residual stresses were found in the vicinity of the weld, $6 \mathrm{~mm}$ below the outer surface, with the lower tensile stresses 
occurring at the weld toe areas. Axial residual stresses were slightly tensile on the outer surface, close to zero at mid-thickness and compressive at the inner surface.

In Figure 10, the residual stress maps of $\mathrm{P}_{\mathrm{HT}} 1$ (local PWHT) and $\mathrm{P}_{\mathrm{HT}^{2}} 2$ (in furnace) after PWHT are presented, indicating a significant reduction in residual stress distributions. Stresses in $\mathrm{P}_{\mathrm{HT}} 2$ are almost relieved via conventional furnace $\mathrm{PWHT}$. The remaining stresses are distributed evenly inside the pipe and the magnitudes are less than 100 MPa which is less than $20 \%$ of the parent metal room temperature yield strength. In $\mathrm{P}_{\mathrm{HT}} 1$, a slight variation of stress in the weld and the metal nearby can be observed. Near the pipe outer surface, the stresses are lower and of a tensile nature in the hoop direction. At the inner surface, the stresses are also lower but of a compressive nature in the axial direction. This variation disappears beyond the toe and the stress state in the far field is similar to that in $\mathrm{P}_{\mathrm{HT}} 2$.

\section{COMPARISON AND DISCUSION}

Comparison of the through-thickness residual stresses at the weld centre-line and the toe before and after local and furnace PWHT is shown in Figure 11 for the hoop and axial direction respectively, together with the profiles from R6 and BS 7910. The near outer-surface residual stress profiles are also compared with those of R6 estimates, and are shown in Figure 12.

Figure 11 (a) shows that the through-thickness hoop residual stresses at the weld centre of two pipes display overall similar trends to BS 7910 and R6 Level 2 profiles. When the neutron diffraction technique is used with a gauge volume of $3 \times 3 \times 4 \mathrm{~mm}^{3}$, residual stresses at the surface cannot be assessed. The closest measurements to the 
surfaces (both inner and outer) are hence $3 \mathrm{~mm}$ below the surface. As shown in Figure 11 (a), the highest magnitude of the hoop component in the as-welded condition occurs at $6 \mathrm{~mm}(\mathrm{z} / \mathrm{t}=0.69)$ below the outer surface and is close to the upper bound value.

At the weld toe, the hoop stress near the outer surface is $40 \%$ of the room temperature yield strength of the parent metal. Stresses at this location gradually decreases to zero through the wall thickness.

Axial residual stresses near the pipe outer surface are tensile and balanced by compressive residual stress near the inner surface; as shown in Figure 11 (b). The highest axial residual stress is $40 \%$ of the room temperature yield strength of the parent metal. Similar through-thickness stress distribution and magnitude are found at the weld toe. In general, profiles obtained from measurements are below the upper bounds advised in the codes and standards.

The next set of comparisons with the codes is for the line scan $3 \mathrm{~mm}$ below the outer surface. From the measurement results, the two as-welded pipes display identical stress distributions along the line $3 \mathrm{~mm}$ below the outer surface in both the hoop and axial directions (Figure 12), where the hoop stress reaches to $75 \%$ of the yield strength in the weld, then drops to less than $30 \%$ of the yield strength at the toe and reduces to zero $15 \mathrm{~mm}$ away from the weld centre line (Figure 12a). R6 recommendations in the yield zone are conservative. These is a significant advantage in a narrow gap weld procedure for its lower heat input and smaller HAZ, in consequence, lower residual stresses.

Axial residual stresses (Figure 12b) are predominantly tensile near the outer surface in the as-welded condition. $3 \mathrm{~mm}$ below the outer surface, axial residual stresses are 
tensile, up to $55 \%$ of the material yield strength in the HAZ. After PWHT, they are found less than $20 \%$ of the material yield strength.

PWHT is successful in reducing residual stresses in both pipe spools (Figures 11-12). At the weld centre line, axial residual stress in $\mathrm{P}_{\mathrm{HT}} 2$ was greatly reduced to approximately zero. For $\mathrm{P}_{\mathrm{HT}} 1$, which was heated locally, stresses at the inner surface were reduced to $20 \%$ of the material yield strength. Comparing the stress reduction in general, it can be considered that the local PWHT in this study exhibits nearly the same stress relief effect as by furnace heating.

The finding of this work has been shared with the chair of BS7910 committee. The R6 committee has also been made aware of this work. The committee will process the data, and reference will be made when they see fit.

\section{CONCLUSIONS}

In this paper, residual stresses were determined in narrow gap girth welds in the aswelded condition and after global and local PWHT. The stress states at locations near the outer surface and through the pipe thickness were compared with the recommended upper bound profiles in engineering critical assessment codes and standards BS 7910 and R6. The key findings of this study:

1. Small temperature differences during preheating do not affect the overall residual stress state of pipe spools after welding fabrication.

2. Current recommendations in the codes are generally conservative for the narrow gap welding procedures in both as-welded and PWHT conditions. 
3. Local PWHT can achieve the same magnitude of stress relief as that of global PWHT, if it is applied correctly, following prescribed procedure.

4. With regard to narrow gap multi pass welds, it is suggested that residual stresses may be relieved effectively by local PWHT using reduced width of the standard heating band which are recommended in general practice.

\section{ACKNOWLEDGMENTS}

This project was co-funded by Brunel University London and the National Structural Integrity Research Centre (NSIRC). The authors acknowledge the support of the Bragg Institute, Australian Nuclear Science and Technology Organisation, in providing the neutron research facilities used in this work.

\section{NOMENCLATURE}

D Pipe outside diameter, $\mathrm{mm}$

$t \quad$ Pipe wall thickness, $\mathrm{mm}$

$D / t \quad$ Pipe standard dimension ratio

$P_{\text {AW }} \quad$ Pipe spool in as-welded condition

$P_{H T} 1 \quad$ Pipe spool after local post weld heat treatment

$P_{H T} 2 \quad$ Pipe spool after furnace post weld heat treatment

$\sigma_{y}^{+} \quad$ The higher value of the yield strength (at room temperature) of the weld or parent material, $\mathrm{MPa}$

$\sigma_{y}^{*} \quad$ The lower value of the yield strength (at room temperature) of the weld 
Journal of Pressure Vessel Technology

or parent material, $\mathrm{MPa}$

$\sigma_{R}^{L, O} \quad$ Longitudinal (hoop) thought-thickness residual stress at pipe outer surface, MPa

$\sigma_{R}^{L, B} \quad$ Longitudinal (hoop) thought-thickness residual stress at the bore (inner surface), $\mathrm{MPa}$

$\sigma_{R}^{T} \quad$ Transverse (axial) residual stress through the pipe wall thickness, MPa

$r_{0} \quad$ Radius of the yield zone, $\mathrm{mm}$ 


\section{REFERENCES}

[1] E. J. Hearn, "Contact stress, residual stress and stress concentrations," in Mechanics of Materials-2An Introduction to the Mechanics of Elastic and Plasyic Deformation of Solids and Structural Materials, Third Edit., 1997, pp. 381-442.

[2] A. M. Paradowska, J. W. H. Price, R. Ibrahim, and T. R. Finlayson, "The effect of heat input on residual stress distribution of steel welds measured by neutron diffraction," J. Achiev. Mater. Manuf. Eng., vol. 17, no. 1-2, pp. 385-388, 2006.

[3] R. F. D. Scaramangas, A. and Porter Goff, "Residual stress and deformation in welded pipe joints.," in Joints in Structural Steelwork, Proc. Int. Conf., 1981.

[4] R. H. Leggatt, "Residual stressesat girth welds in pipes," Weld. Energy-Related Proj., pp. 429-440, 1984.

[5] N. S. Rossini, M. Dassisti, K. Y. Benyounis, and A. G. Olabi, "Methods of measuring residual stresses in components," Mater. Des., vol. 35, pp. 572-588, Mar. 2012.

[6] P. Withers and H. Bhadeshia, "Residual stress. Part 1-measurement techniques," Mater. Sci. Technol., vol. 17, no. April, pp. 355-365, 2001.

[7] B. Chen, A. Skouras, Y. Q. Wang, J. F. Kelleher, S. Y. Zhang, D. J. Smith, P. E. J. Flewitt, and M. J. Pavier, "In situ neutron diffraction measurement of residual stress relaxation in a welded steel pipe during heat treatment," Mater. Sci. Eng. A, vol. 590, pp. 374-383, Jan. 2014.

[8] R. D. Haigh, M. T. Hutchings, J. a. James, S. Ganguly, R. Mizuno, K. Ogawa, S. Okido, a. M. Paradowska, and M. E. Fitzpatrick, “Neutron diffraction residual stress measurements on girth-welded 304 stainless steel pipes with weld metal 
deposited up to half and full pipe wall thickness," Int. J. Press. Vessel. Pip., vol. 101, pp. 1-11, Jan. 2013.

[9] T. Neeraj, T. Gnäupel-Herold, H. J. Prask, and R. Ayer, "Residual stresses in girth welds of carbon steel pipes: neutron diffraction analysis," Sci. Technol. Weld. Join., vol. 16, no. 3, pp. 249-253, Apr. 2011.

[10] D N Crofft, Heat Treatment Of Welded Steel Structures. 1996.

[11] "BSI, 'BS7910:2013 Guide to methods for assessing the acceptability of flaws in metallic structures,' 2013."

[12] W. Soete and R. Vancrombrugge, "An industrial method for the determination of initial stresses," Proc SESA, vol. 8, no. 1, pp. 17-28, 1950.

[13] R. T. Rose, "Stress in Cylindrical Vessels due to Local Heating Stress Relief of Circumferential Welds," Br. Weld. J., pp. 19-21, 1960.

[14] J. I. Bluhm, Fracture Mechanics. 1963.

[15] H. MURAKAWA, H. LU, and J. WANG, “Mechanical Behavior in Local Postweld Heat Treatment (Report II) : Determination of Critical Heated Band during Local PWHT(Mechanics, Strength \& Structure Design)," Trans. JW RI, vol. 27, pp. 89-95, 1998.

[16] E. G. Shifrin and M. I. Rich, "Effect of Heat Source Width in Local Heat Treatment of Piping," Weld. J., vol. 53, no. 12, pp. 792-799, Dec. 1973.

[17] C. Bloch, J. Hill, and D. Connell, "Proper PWHT Can Stop Stress-Induced Corrosion," Weld. J., vol. 76, no. 5, pp. 31-41, 1997.

[18] H. LU, J. WANG, and H. MURAKAWA, "Mechanical Behavior in Local Postweld 
Heat Treatment (Report III) : Criteria for heated band width based on throughthickness temperature distribution(Mechanics, Strength \& Structure Design)," Trans. JW RI, vol. 27, pp. 89-95, 1998.

[19] I. Milne, R. . Ainsworth, A. . Dowling, and A. . Stewart, "Assessment of the integrity of structures containing defects," Int. J. Press. Vessel. Pip., vol. 32, no. 14, pp. 3-104, Jan. 1988.

[20] Y. C. Lin and K. H. Lee, "Effect of preheating on the residual stress in type 304 stainless steel weldment," J. Mater. Process. Technol., vol. 63, pp. 797-801, 1997.

[21] S. M. Adedayo and M. B. Adeyemi, "Effect of preheat on residual stress distributions in arc-welded mild steel plates," J. Mater. Eng. Perform., vol. 9, no. 1, pp. 7-11, 2000.

[22] G. a. Webster and R. C. Wimpory, "Non-destructive measurement of residual stress by neutron diffraction," J. Mater. Process. Technol., vol. 117, no. 3, pp. 395-399, Nov. 2001.

[23] a Stacey, H. J. MacGILLIVARY, G. a Webster, P. J. Webster, and K. R. a Ziebeck, "Measurement of residual stresses by neutron diffraction," J. Strain Anal. Eng. Des., vol. 20, no. 2, pp. 93-100, Apr. 1985.

[24] T. Manns; B. Scholtes, “DECcalc - A Program for the Calculation of Diffraction Elastic Constants from Single Crystal Coefficients," Mater. Sci. Forum, vol. 681, pp. 417-419, 2011.

[25] P. J. Withers, M. Preuss, A. Steuwer, and J. W. L. Pang, "Methods for obtaining the strain-free lattice parameter when using diffraction to determine residual stress 
research papers," J. Appl. Crystallogr., vol. 40, pp. 891-904, 2007.

[26] Y. Ren, A. Paradowska, E. Eren, and B. Wang, "Challenges of Measuring Residual Stresses in Large Girth Welded Pipe Spools by Neutron Diffraction," Mater. Res. Proc., vol. 2, pp. 575-580, 2017.

[27] J. R. Taylor, An Introduction to Error Analysis. Oxford University Press, 1982.

[28] A. J. Allen, "Errors in Analysis, in Measurement of Residual and Applied Stress Using Neutron Diffraction," 1992.

[29] ANSI/AWS D10.10/10.10M, Recommended Practices for Local Heating of Welds in Piping and Tubing,An American National Standard. 1999.

[30] "A Review of Post Weld Heat Treatment Effects on Welding Residual Stresses For : R6 Panel A Review of Post Weld Heat Treatment Effects on Welding Residual Stresses," no. April, 2014. 


\section{Figure Captions List}

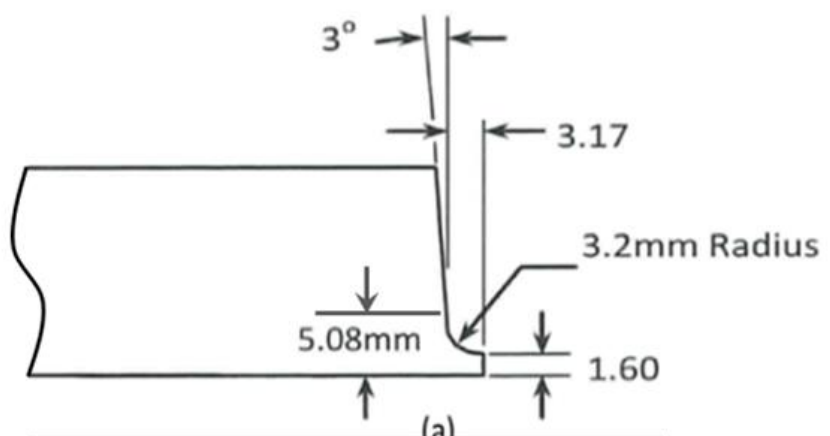

(a)

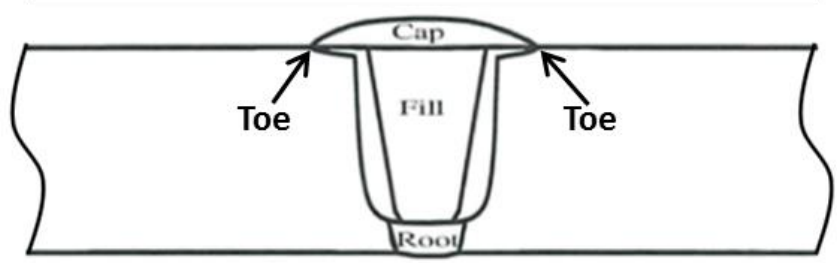

(b)

Fig. 1 (a) Geometrical details of the weld groove and (b) Schematic representation of the welding procedure

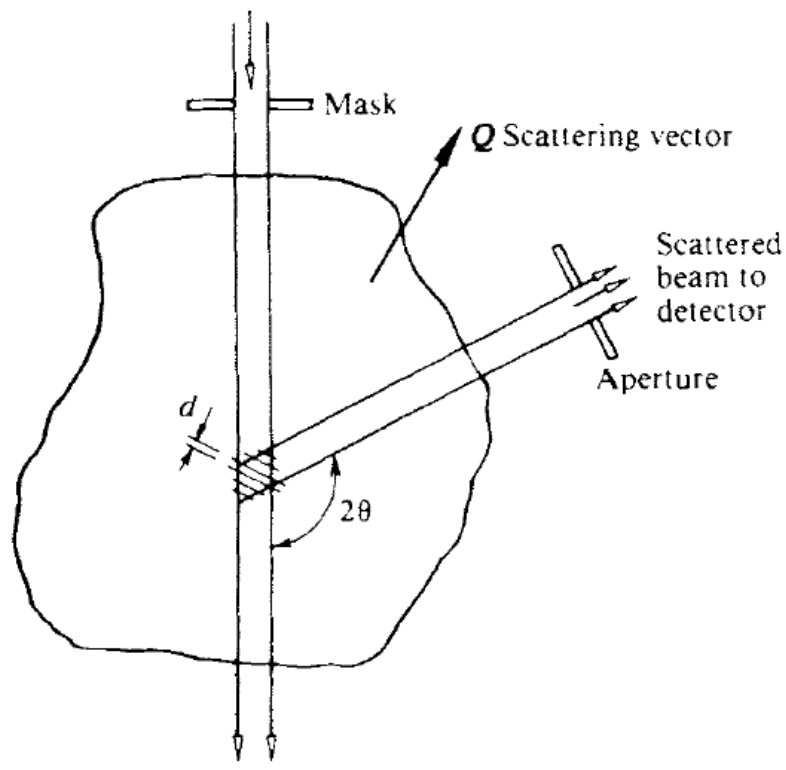

Fig. 2 Principles of neutron diffraction[23] 


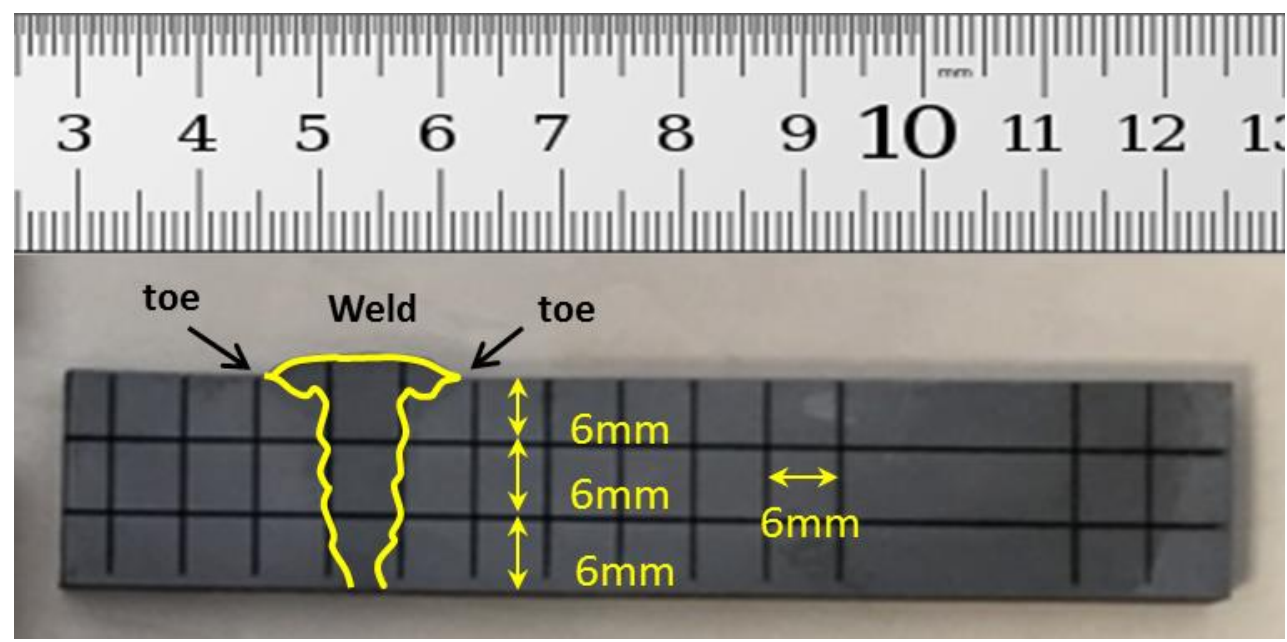

Fig. 3

Overview of the comb reference specimen

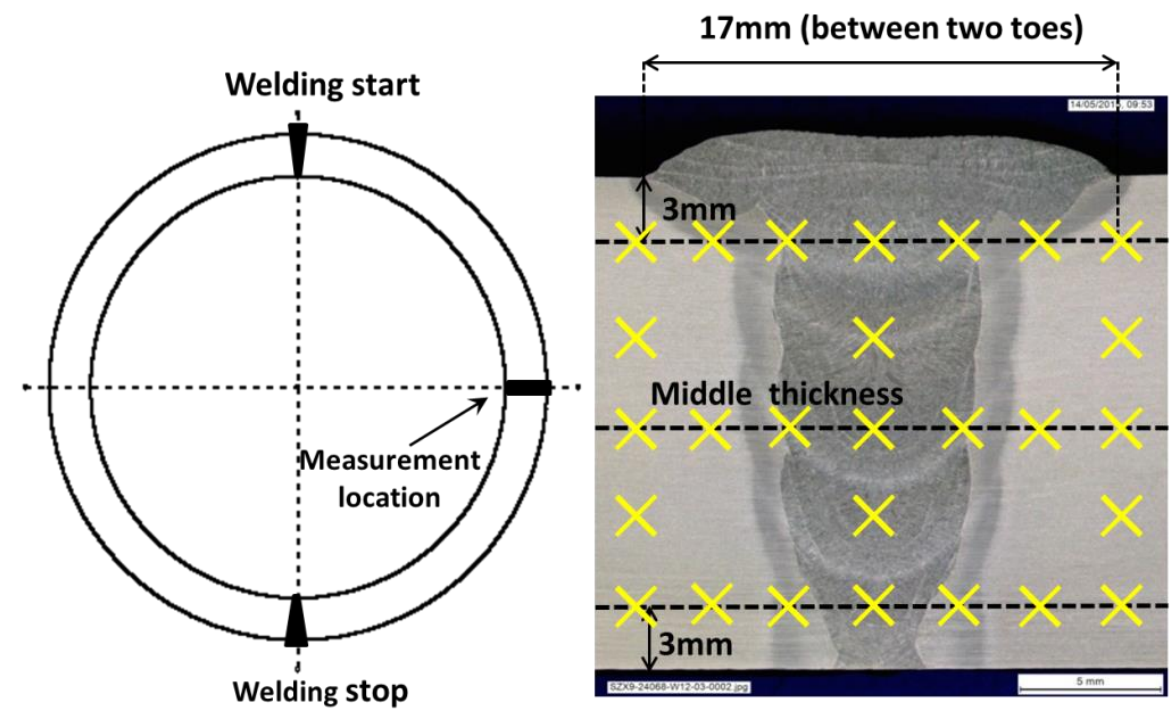

Fig. 4 Schematic overview of the welding procedure (left), Macrograph of the weld cross section and measurement points in the vicinity of the weld centre (right). 


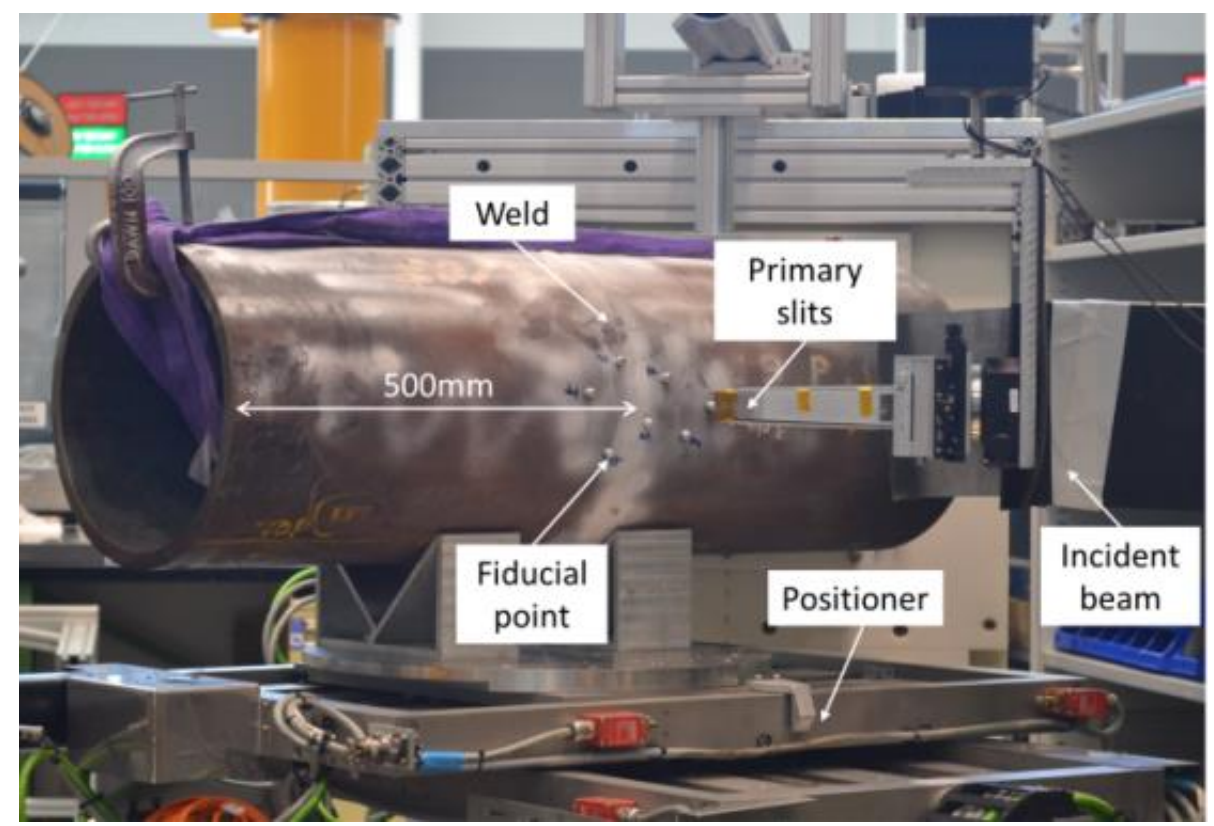

Fig. 5

Measurement of the axial residual strains in the pipe spool on KOWARI instrument at ANSTO

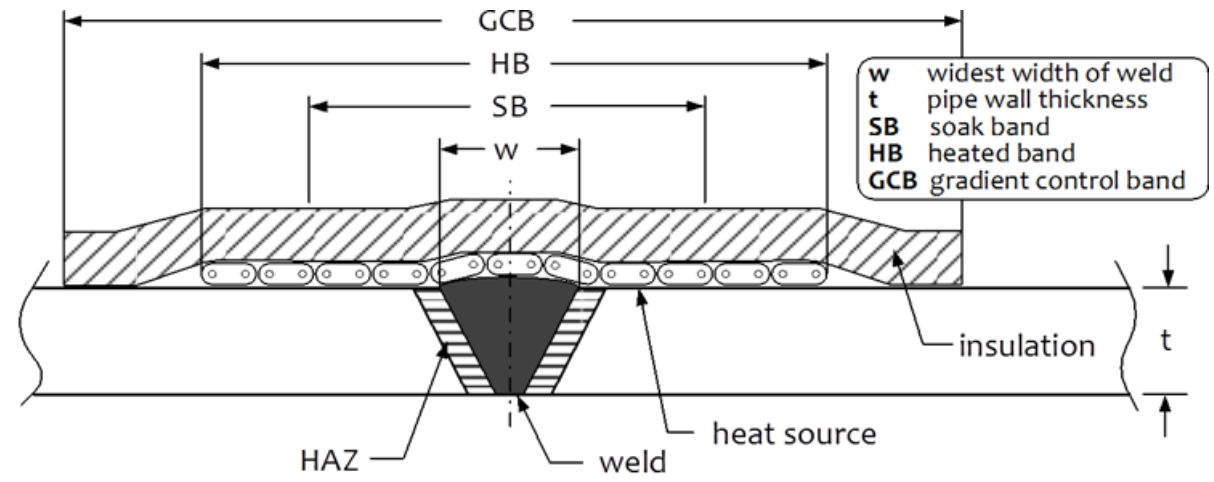

Fig. 6 Sketch of the parameters for local circumferential PWHT [29] 


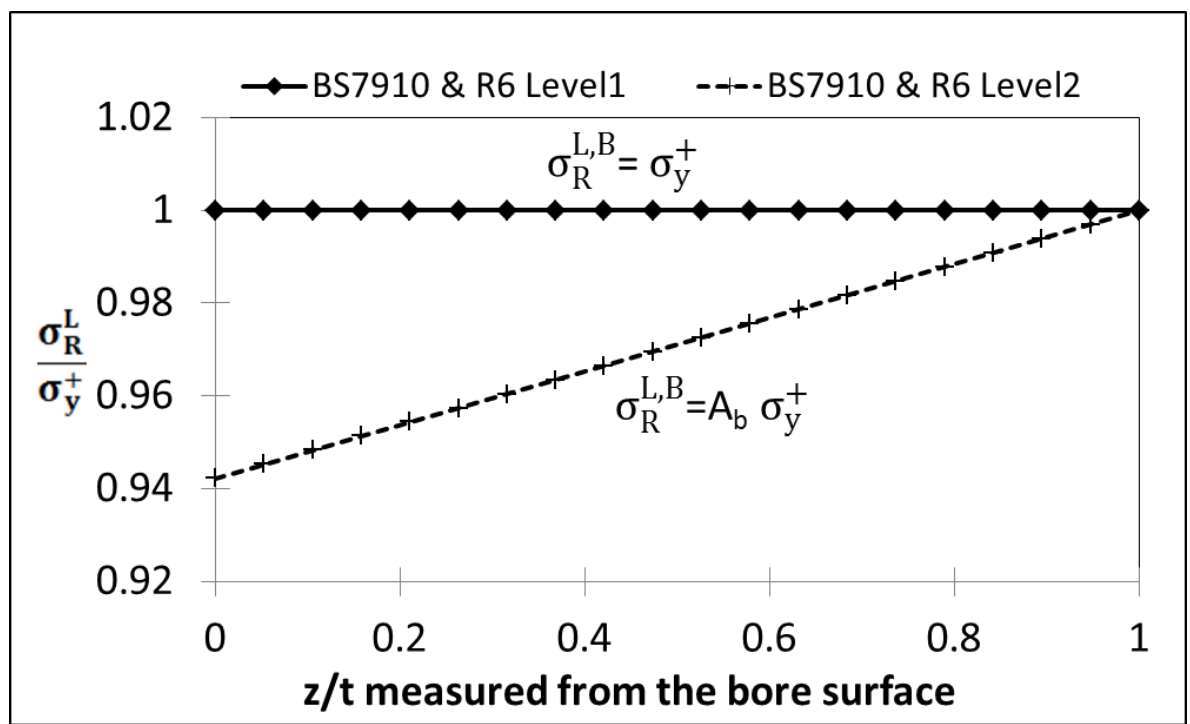

(a) Longitudinal( hoop direction in pipe) stress distribution

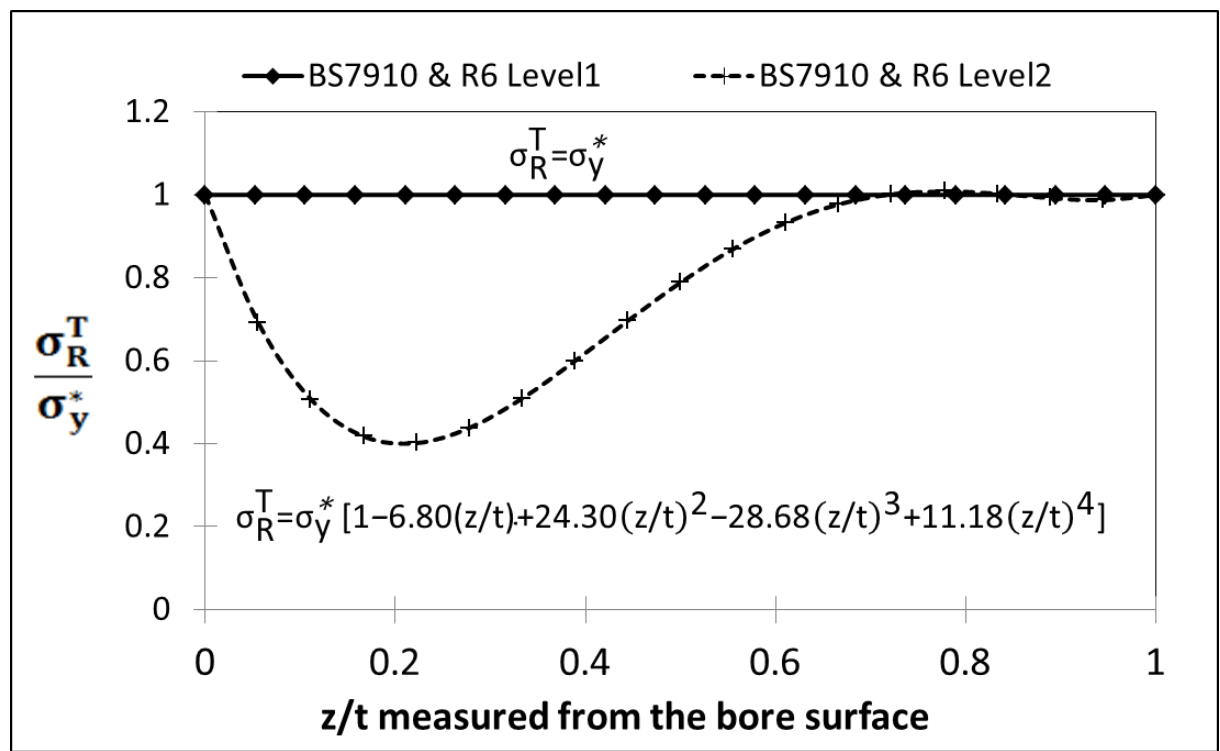

(b) Transverse (axial direction in pipe)stress distribution

Fig. 7 Calculated Level 1 and Level 2 through-thickness residual stress distribution based on BS 7910 and R6 [19], [30] 


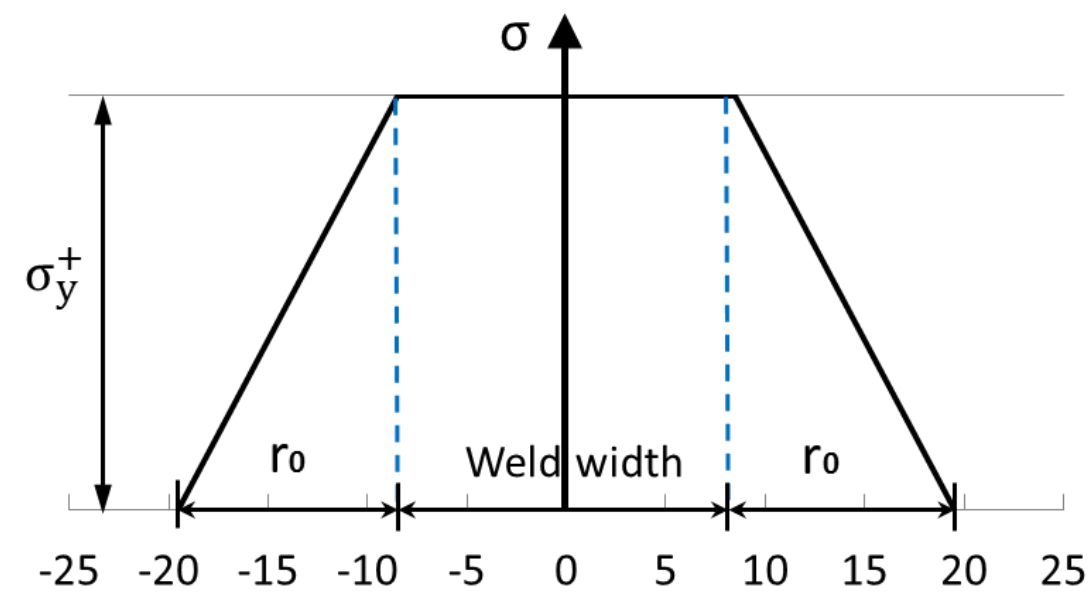

Fig. 8 Surface longitudinal residual stress distribution and calculated radius of the yield zone at butt weld in the pipe [19]

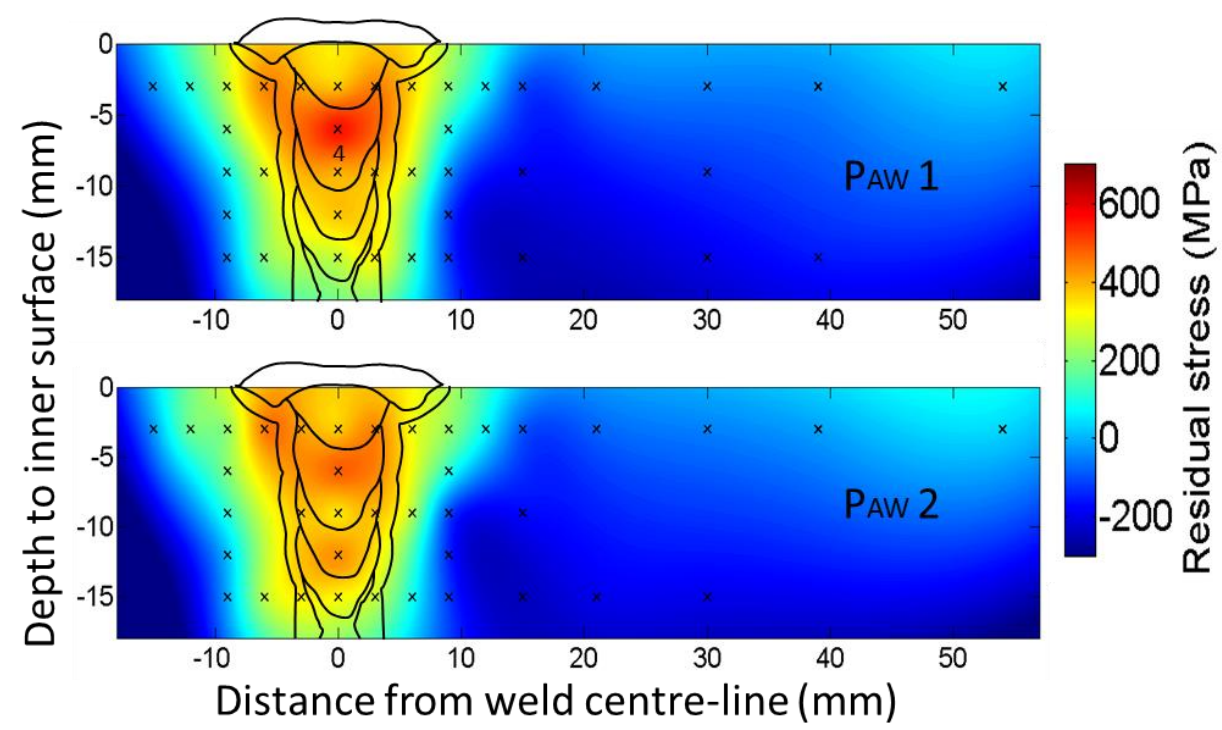

(a) 


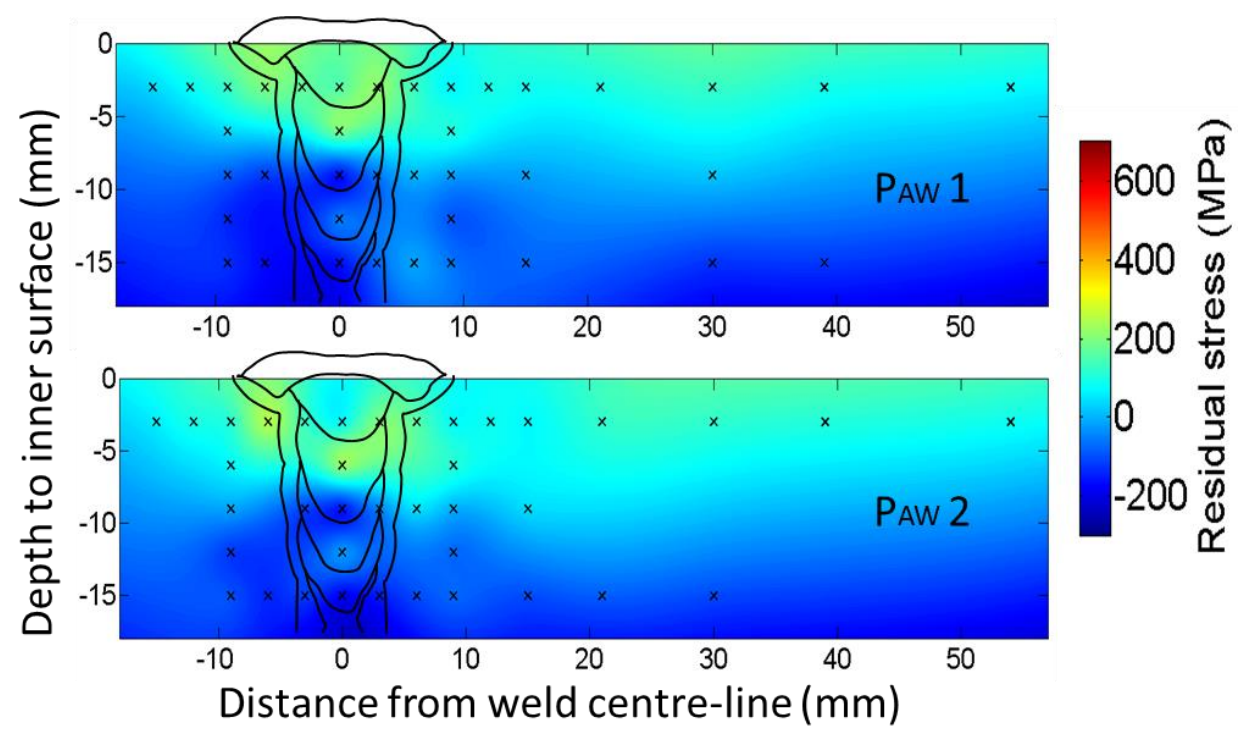

(b)

Fig. 9 Residual stress maps in as-welded condition in hoop (a) and axial (b) direction for $\mathrm{P}_{\mathrm{AW}} 1$ and $\mathrm{P}_{\mathrm{AW}} 2$

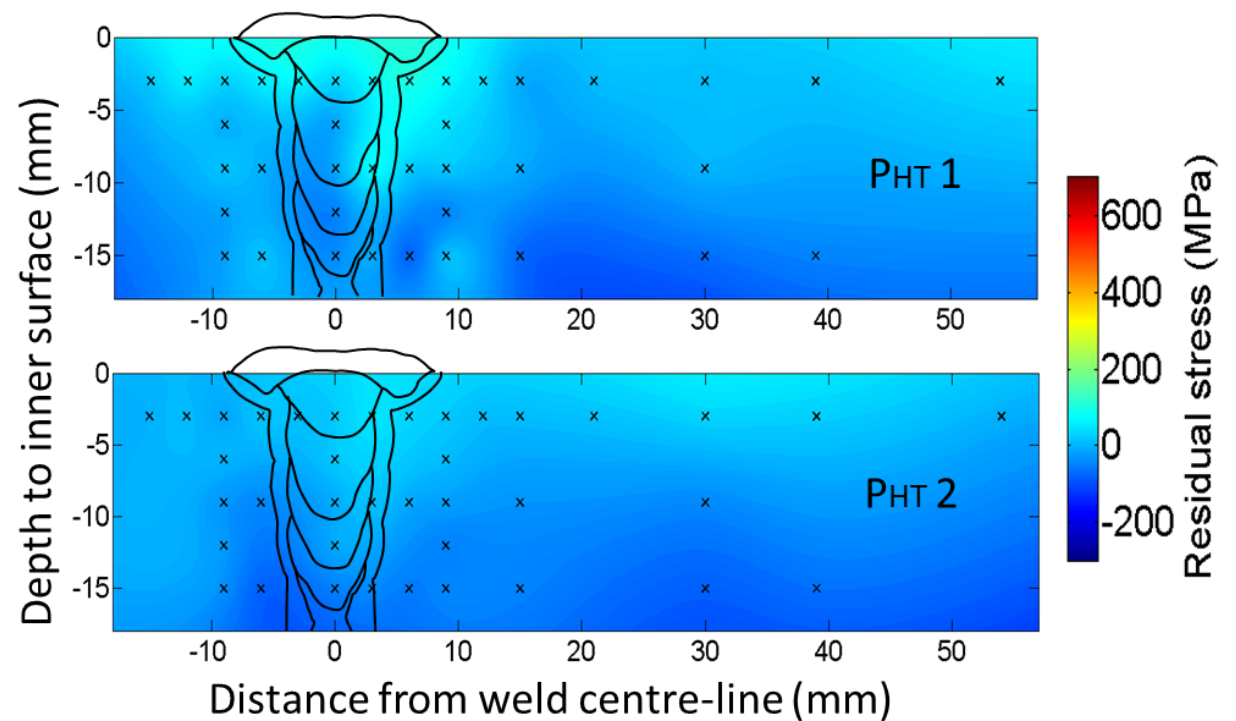

(a) 


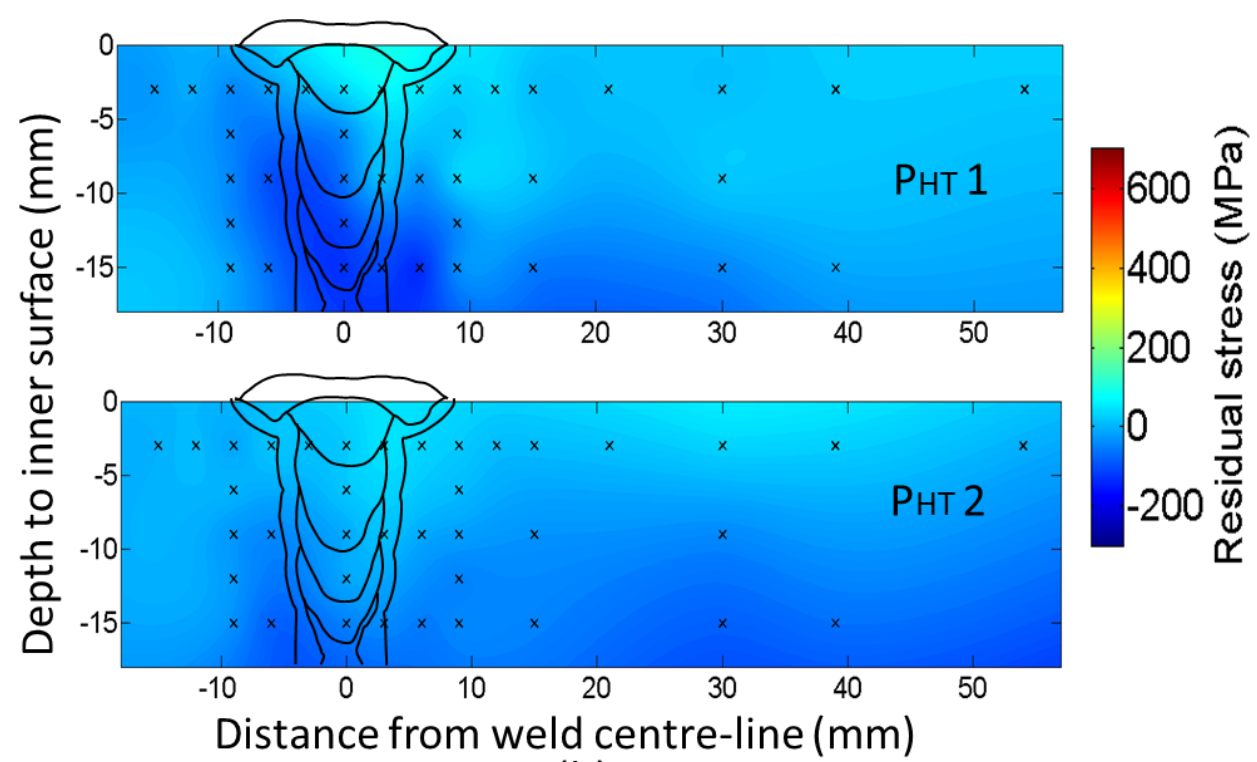

(b)

Fig. 10 Residual stress maps in after PWHT in hoop (a) and axial (b) direction for $\mathrm{P}_{\mathrm{HT}} 1$ and $\mathrm{P}_{\mathrm{HT}} 2$

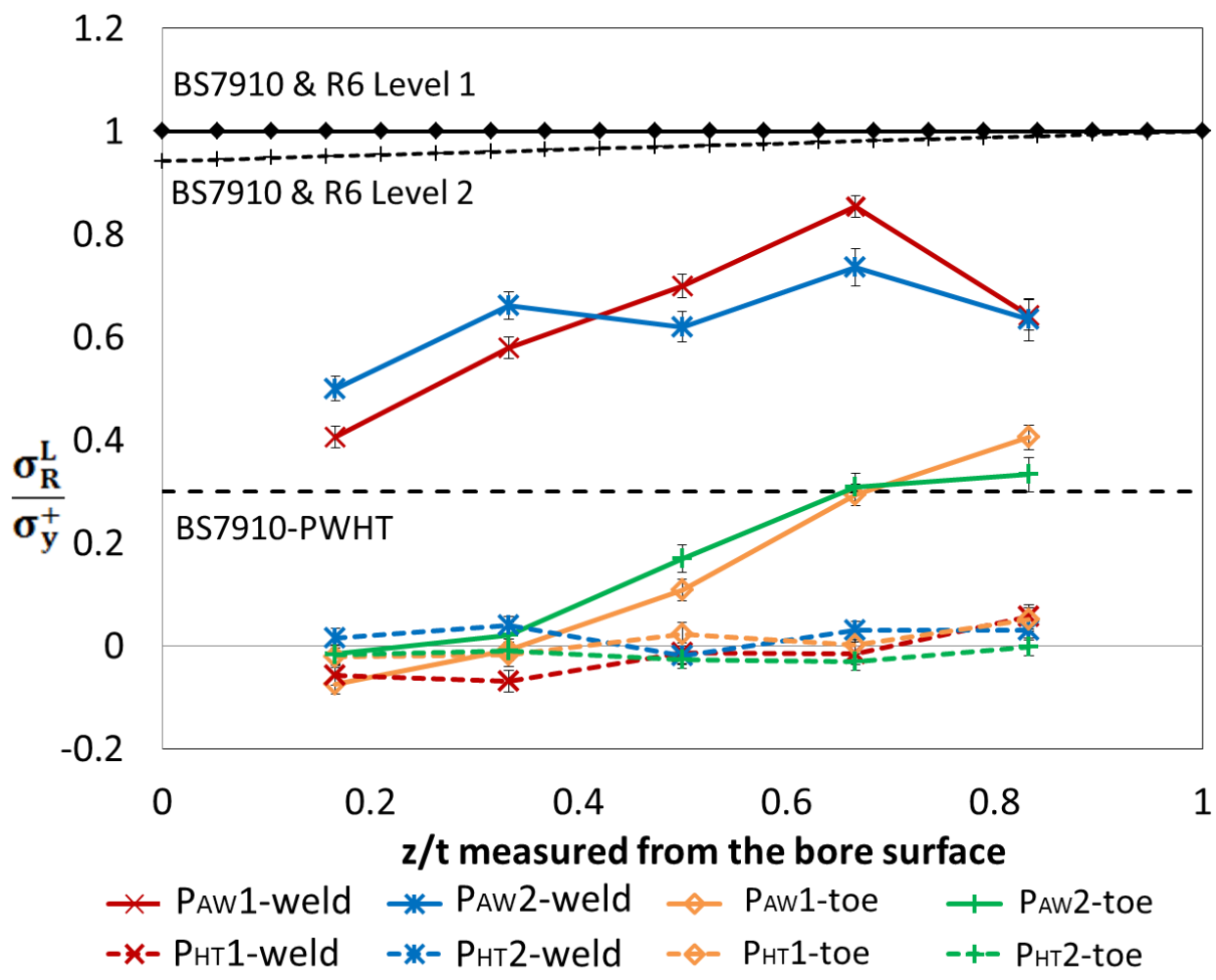

(a) Normalized hoop residual stresses 


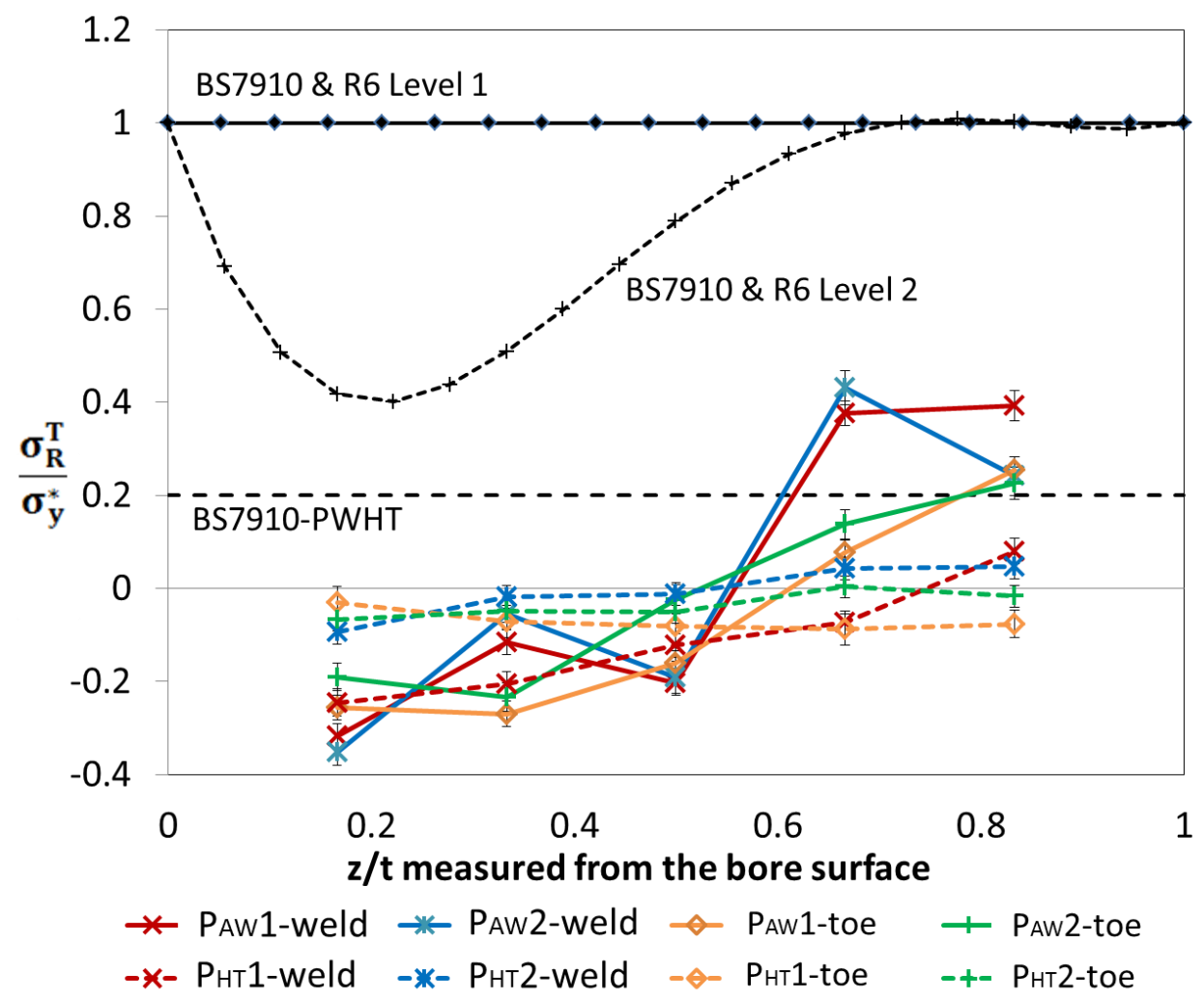

Fig. 11 Comparison of the through-thickness residual stresses at weld centre and weld toe before and after local and furnace PWHT with R6 and BS 7910

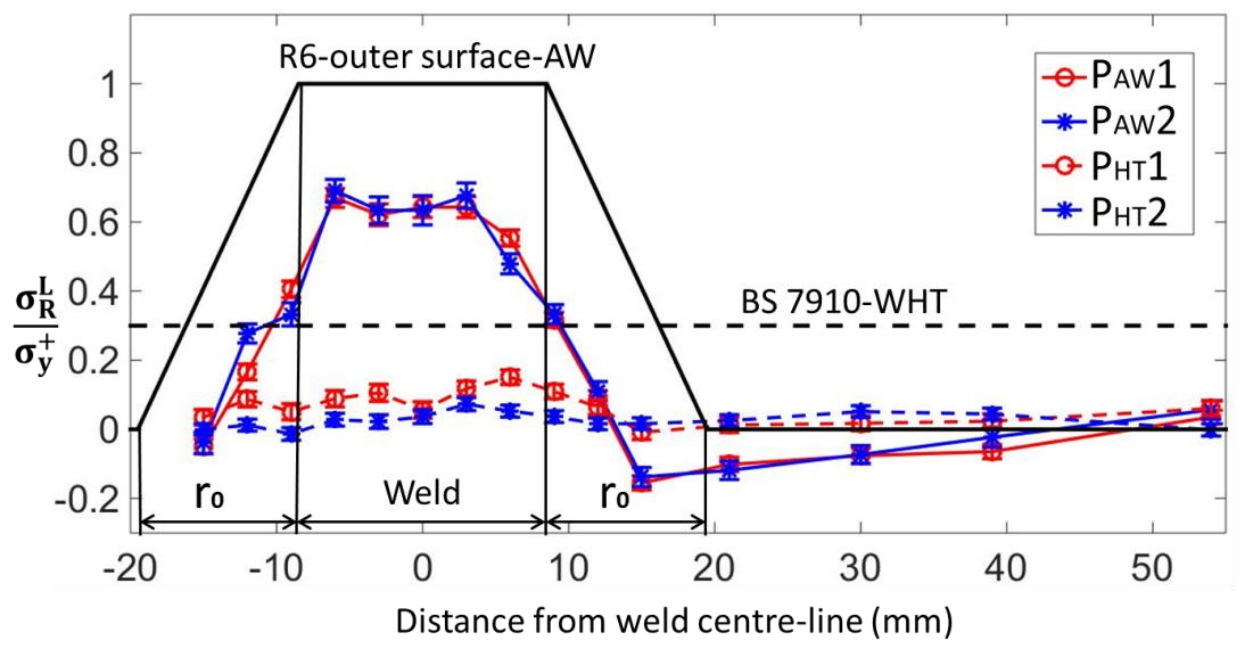

(a) Normalized hoop residual stresses 
Journal of Pressure Vessel Technology

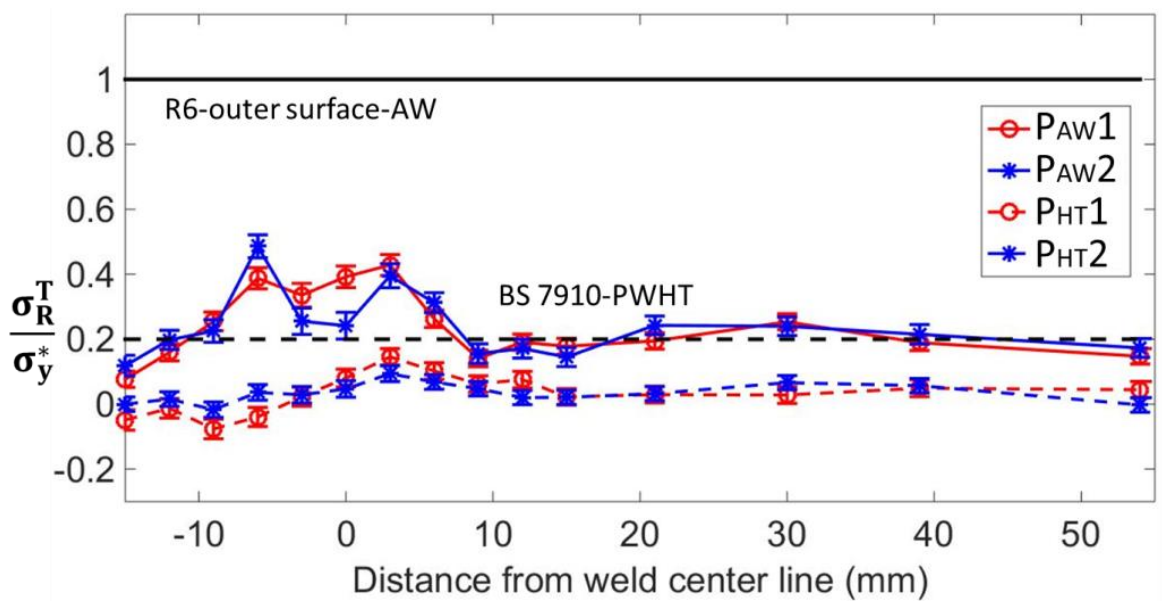

(b) Normalized axial residual stresses

Fig. 12 Comparison of the near outer-surface residual stress before and after local and furnace PWHT with R6 and BS 7910-PWHT 
Journal of Pressure Vessel Technology 


\section{Table Caption List}

Table 1 Chemical compositions of the materials

\begin{tabular}{c|cccccccc}
\hline \multirow{2}{*}{ material } & \multicolumn{8}{|c}{ Composition (wt\%) } \\
& $\mathrm{C}$ & $\mathrm{Mn}$ & $\mathrm{Si}$ & $\mathrm{Ni}$ & $\mathrm{Cr}$ & $\mathrm{Mo}$ & $\mathrm{V}$ & $\mathrm{Cu}$ \\
\cline { 1 - 6 } $\begin{array}{c}\text { Parent } \\
\text { metal }\end{array}$ & 0.1 & 1.13 & 0.25 & 0.11 & 0.14 & 0.1 & 0.06 & 0.16 \\
\cline { 1 - 3 } \\
$\begin{array}{c}\text { Fill } \\
\text { metal }\end{array}$ & 0.07 & 1.55 & 0.68 & 0.92 & 0.03 & 0.004 & 0.008 & 0.08 \\
\hline
\end{tabular}

Table 2 Tensile properties of the parent and weld metal obtained from tests carried out at room temperature

\begin{tabular}{c|cc}
\hline $\begin{array}{c}\text { Mechanical } \\
\text { properties }\end{array}$ & $\begin{array}{c}\text { Yield strength (MPa) } \\
\text { 0.2\% proof stress }\end{array}$ & UTS (MPa) \\
\hline $\begin{array}{c}\text { Parent metal } \\
\text { (specified) }\end{array}$ & 510 & 600 \\
Weld metal & $(460-580)$ & $(550-700)$ \\
\hline
\end{tabular}

Table $3 \quad$ Welding parameters for $X 65$ pipes

\begin{tabular}{l|ccc}
\hline \multicolumn{1}{c|}{ parameters } & Root & Hot pass/fill & cap \\
\hline Shielding gas composition & \multicolumn{3}{c}{ 50\%Ar / 50\%CO } \\
Flow rate (I/min) & 28 & 28 & 28 \\
Filler wire diameter $(\mathrm{mm})$ & 1.0 & 1.0 & 1.0 \\
Voltage (V) & $14-15$ & $21-22$ & $21-22$ \\
Current $(\mathrm{A})$ & $210-230$ & $150-220$ & $120-130$ \\
polarity & $\mathrm{DC}+$ & $\mathrm{DC}+$ & $\mathrm{DC}+$ \\
Travel speed $(\mathrm{mm} / \mathrm{s})$ & $5.8-6.2$ & $4.8-7$ & $3.1-4.5$ \\
Heat input $(\mathrm{kJ} / \mathrm{mm})$ & $0.5-0.55$ & $0.6-0.9$ & $0.6-0.9$ \\
\hline
\end{tabular}


Journal of Pressure Vessel Technology

Table $4 \quad$ PWHT methods and parameters for the two pipes

\begin{tabular}{l|cc}
\hline PWHT & $P_{H T} l$ & $P_{H T} 2$ \\
\hline Method & Local & Furnace \\
Heating band $(\mathrm{mm})$ & $280 \mathrm{~mm}$ & $1000 \mathrm{~mm}$ \\
Gradient control band $(\mathrm{mm})$ & $500 \mathrm{~mm}$ & no \\
Heating rate $\left({ }^{\circ} \mathrm{C} / \mathrm{h}\right)$ & 200 & 200 \\
Soaking temperature $\left({ }^{\circ} \mathrm{C}\right)$ & 620 & 620 \\
Soaking time $(\mathrm{h})$ & 1 & 1 \\
Cooling rate $\left({ }^{\circ} \mathrm{C} / \mathrm{h}\right)$ & 220 & 220 \\
\hline
\end{tabular}

